\title{
16. Is There a Command Culture in Politics? The Canberra Case
}

\author{
James Walter
}

\section{The rise of the command culture}

My recent concern has been with the conditions that encourage political leaders to 'go too far', that is, to override the constraints that not only reinforce democracy by diffusing power, but also that contribute to good policy-making by enforcing recurrent reality checks (Walter 2006). Part of the story is about the proclivities within leaders themselves, but part, too, is about the historical, sociological and cultural changes that have eroded the institutional barriers to leadership caprice. Studies of leadership psychology have alerted us to predictable patterns of leadership behaviour (Walter 2007a; Walter 2007b), but these must be seen in conjunction with institutional transformations. I want here to explore a proposition: that recent institutional change has been conducive to the evolution of a 'command culture' that is potentially anti-democratic.

Such a proposition is not peculiar to Australia: it is part of a wider debate about the consolidation of executive power, sometimes discussed in terms of 'presidentialisation' (Poguntke and Webb 2005). Nor is the personalisation of politics around commanding leaders without parallels elsewhere: it is much discussed, for instance, in the literature on Tony Blair (Kampfner 2003; Coates and Krieger 2004; Hennessy 2005). Yet both institutional factors and the proclivities of individual leaders endow every instance with uniqueness and my argument is that the Australian case has not been closely enough studied.

While I will focus here on John Howard's government, similarities can be seen in the practices of state premiers (see Wanna and Williams 2005). As Paul Strangio and I argue in a recent book, No, prime minister (Walter and Strangio 2007), the underlying trend long predates Howard; the phenomenon is much more widespread and it will continue - Howard is simply a convenient exemplar. The demise of his government prompts the question: does a new government presage a new approach? My analysis suggests: not necessarily.

\section{From dispersed to concentrated leadership}

Democracy is premised upon avoidance of leadership dominance. It assumes that individuals will be driven by self-interest and that elites will emerge, but the demos will be protected by countering power with power - the checks and balances of countervailing institutions. John Uhr's concept of 'the lattice of leadership' is a useful gloss on this point - leadership diffused across 
institutional spheres, but constrained to work collectively for the common good, with each elite challenged to do its best by being held to account by leaders in another sphere (Uhr 2005: 78-81). When one element becomes too dominant, the ethical constraint of the lattice breaks down. The counterpoint is that when power is allowed to aggregate, democracy is threatened.

Many have noted the tendency towards the aggregation of executive power. Uhr himself provides a valuable chapter on national security initiatives as a war against ethics and an assault on 'the lattice of leadership' (Uhr 2005: ch. 7). Ian McAllister has carefully plotted the trends accentuating prime ministerial leadership, while noting that particular personalities tend to accelerate or to contain those trends (McAllister 2008). Jenny Hocking provocatively claims that we are witnessing the emergence of post-democratic leadership, with closed and secretive decision-making depending on an assertion that contemporary government is dealing with matters of such moment and urgency that an elision conflating its interests with those of the state can be taken for granted, at the expense of community consultation, parliamentary oversight and judicial review (Hocking 2005). At the national level, this also justifies overriding federal devolution and local government.

Such arguments can be related to cumulative institutional changes in our political system. These include the conduct of prime ministers over at least the past three decades; reforms to the public service to make the bureaucracy more responsive to incumbent governments (with the centralisation of policy co-ordination and authority in the Department of the Prime Minister and Cabinet and through it the Prime Minister); the development of dense and highly centralised political advisory structures; the evolution of media conventions that draw attention to leaders and the 'story' of personality conflicts rather than to policy debate; and the hollowing out of political parties which once acted as a brake on politicians, including leaders (Walter and Strangio 2007).

The dynamic is illuminated in the patterns of decision making relating to the commitment to war and the response to terrorism, as Uhr (2005), Hocking (2005), Walter (2006) and many others have argued. It is not surprising that, for decision-makers, crisis situations provoke concern about the security of information, inhibit open communication, reinforce 'inner circle' interaction, and are conducive to 'groupthink'. It is for these reasons that war and foreign policy are favoured by theorists such as Irving Janis (1982) and Graeme Allison (1971). Recently, others (for example, Preston and 't Hart 1999) have shown the broader potential for groupthink, where the leader's needs demonstrably affect the organisation and operation of advisory systems in bureaucratic politics. Taking this lead, Strangio and I concentrated on domestic policy making, arguing that, with the erosion of institutional constraints, leader-centric policy making 
has become more and more the norm across the policy terrain, and not just in relation to war, terrorism and foreign policy.

In broad terms, this might be seen as an incremental progression in the case of the Howard government. Howard did not, in the main, by-pass cabinet. He was both committed to, and respectful of, cabinet government (Weller 2007: ch. 10); he listened to colleagues and exerted discipline effectively, but cabinet became an instrument of his dominance (Kelly 2005). Yet, what was once the exception, when Howard by-passed cabinet to work with a small inner circle — such as in the 'exceptional' circumstance of the 'children overboard affair' (Weller 2002), or the secretive decision-making surrounding the Iraq commitment (Walter 2006) - became, increasingly, the tactic of choice the longer he was in power.

This syndrome was particularly evident in 2007, when there was what amounted to a year-long election campaign. In the theatre of campaigning, politicians' minds were concentrated on the battle for power and, suddenly, social problems of lengthy duration were starkly revealed as now being urgent and so challenging that only an experienced government (the Coalition) could manage, or that only 'new leadership' (Labor) could break through.

Dramatic responses in such cases as described below have revealed a style of decision-making that should concern us. Initiatives were driven by leaders (to the detriment of community consultation), tactics were fundamentally illiberal (the urgency of action used as a licence to break down the 'normal' checks and balances), and the strategy was essentially undemocratic (as power aggregated at the top).

The characteristic pattern was to transform a matter that might normally be seen as subject to routine processes of policy deliberation into a crisis, giving discretion to the leader to override the usual (democratic) provisions (cf. Marrs 2001: 25) and, incidentally, legitimating extreme centralisation of decision making ('t Hart, Rosenthal and Kouzmin 1993; Kouzmin 2008). Thus, a number of crises were identified - social breakdown in Indigenous communities, the states' administration of hospitals, water management, for instance - and it was argued that only central government intervention and strong leadership could serve as the circuit breaker. The government would make a forceful statement (such as, 'the army will arrive next week') in advance of community consultation. Labor occasionally engaged in its own pre-emption, trying to second guess government intentions, and announcing its position - usually no less top-down, no less leader-centric - in advance of government action.

Other authorities (local and state governments especially) were overridden or attacked as barriers to the resolution of national problems. Liberal institutions (the federal devolution of power, parliamentary scrutiny, the courts), whose purpose is to guard against capricious government, were diminished. There was a devaluation of local knowledge and of the wisdom of those with hands-on 
experience of those areas the policy community now determined to take over. Despite rhetorical gestures towards community engagement, there was rarely any commitment to co-operative management regimes.

\section{Command in action: the NT intervention case}

I will use one case to illustrate the argument: the Howard government's intervention into Indigenous communities in mid-2007. It exemplified a pattern of policy making said to be driven by the dimensions of the crisis it sought to address, but which is indicative of a broader tendency in the domestic policy arena - the command culture. I do not gainsay the extent of the problem: none could doubt the social dysfunction in some of the Indigenous communities targeted, or the failure of prevailing policy regimes. Nor do I question the intentions of the advocates of the intervention policy, or concentrate upon its alleged ideological subtexts. Instead, I explore those things the policy community seems to accept as 'givens' in such an approach.

The catalyst for intervention was Little Children are Sacred, a report by Rex Wild and Pat Anderson on the sexual abuse of children in Indigenous communities (Wild and Anderson 2007), and the failure of the Northern Territory government to act decisively when it was released. In fact, a series of reports, stretching back at least 18 years to Judy Atkinson's report on the Northern Territory in a national inquiry on violence, had come to similar conclusions without eliciting such a response. It was significant, however, that Wild and Anderson again dealt with the Northern Territory - the sole jurisdiction in which the Commonwealth government had the power to act more or less unilaterally. To summarise, the government plan encompassed:

- increased police numbers, with support from the army;

- government acquisition of Aboriginal townships for at least five years;

- imposition of community management;

- clean up and repair of community facilities;

- compulsory child health checks;

- school attendance to be enforced;

- welfare payments to be quarantined to 'responsible' families (i.e., those whose children attended school and who complied with hygiene protocols);

- scrapping permits for outsider access to Aboriginal land;

- alcohol bans to be imposed on Northern Territory Aboriginal land; and

- X-rated pornography to be banned (with publicly funded computers to be audited).

The Minister for Indigenous Affairs, Mal Brough, was a former army officer and was widely interpreted as believing that, to quote Tim Rowse, 'if people are behaving in a problematic way, you create a more rigorous framework of rules and enforce that ... [N]o doubt it works in a military setting' (Grattan and 
Chandler 2007). A perceptive newspaper profile described Brough as pursuing 'a frantic quest for swift results in the quagmire of Indigenous affairs':

... everything about him screams haste ... [H]e has been a whirlwind of activity — racing into and out of remote communities, reorganising the bureaucracy and demanding answers and solutions from everyone in his path. The former army officer appears to have internalised the military doctrine that momentum is everything, and this week seized the opportunity of another devastating report to launch a 'shock and awe' blitz $\ldots$ at speed and with scant consultation with Indigenous leaders - hallmarks of the evolving style of the man (Schubert and Murdoch 2007a).

Some in those remote communities concluded, 'he talks, but he doesn't listen'.

Undoubtedly Brough's frantic activity during the year prior to this initiative fed into the policy outcome and cabinet was deeply troubled by the Wild and Anderson report, endorsing the idea that this was an emergency to which the government must respond. An inner group, Howard, Brough, Peter Shergold (the secretary of the Department of the Prime Minister and Cabinet, or PM\&C) and Jeff Harmer (secretary of the then Department of Families, Community Services and Indigenous Affairs, or FaCSIA) then decided that a blueprint for wide-scale intervention was needed. A small team from PM\&C and FaCSIA was told to draw up a plan, (the usual interdepartmental policy process was abandoned), 'and within 72 hours of the ... cabinet meeting the Government unveiled the boldest Aboriginal policy in 40 years' (Karvelas 2007a).

The shadow framework was that provided by Cape York indigenous leader (and public intellectual) Noel Pearson in his long-running campaign against 'passive welfare' (Karvelas 2007a; Rothwell 2007). Pearson has illuminated the destructive effects of entitlement without responsibility. The 'entitlement' to welfare support, he argued, excluded Indigenous people from the real economy and the lack of any expectation of reciprocity defined its recipients as 'hapless and helpless' (Pearson 2000). Helplessness, disillusion and, above all, 'rivers of grog' were seen by Pearson as integral to community dysfunction and child abuse. Thus, he was to endorse the government's intervention: these were, he said, 'cut-through' measures (Schubert and Murdoch 2007b), needed because 'we must stop the suffering straight away' (Pearson 2007). Howard mirrored this view, saying: 'It is interventionist. It does push aside the role of the territory ... But what matters more: the constitutional niceties, or the care and protection of young children?' (The Age, 22 June 2007: 5). Howard was to advance a similar proposition in a number of other cases, for instance, in justifying the take-over of Tasmania's Mersey Hospital. The point to note is that 'constitutional niceties' are what sustain the lattice of leadership. 
Nonetheless, while giving the government credence in its response to this emergency, Pearson had argued for seven years about the necessity for government to engage with the community - progress could only be achieved through state-community partnerships. The harsh welfare crackdown, he said, should apply only in the case of 'responsibility failure' (Schubert and Murdoch $2007 \mathrm{~b}$ ). In relation to the NT intervention, he also argued from its inception that 'as well as policing, there must be a strategy for building Indigenous social and cultural ownership' (Pearson 2007).

No such strategy was evident at any point in the policy process. The consistent defence when this was articulated was (as expressed by Sue Gordon, Chair of the NT Emergency Response Taskforce): 'this was an emergency, and if you have an emergency ... you don't have time to consult people in the initial phases. Every day that there's a delay, that means there's another child at risk' (Karvelas $2007 \mathrm{~b}$ ). Yet the authors of Little Children are Sacred themselves were to condemn the intervention for its failure to engage with target communities. Rex Wild said:

We need long-term strategic work with people, building up trust. We were able to do that in a very short time by, we think, sitting down with people under the trees in the gymnasiums or equivalents and talking with them. That doesn't seem to happen when the bureaucrats arrive (Wild 2007)

The acclaimed reform in Cape York, said Pat Anderson, had been achieved in consultation with Indigenous people: 'There needs to be a radical change in the way government and non-government organisations consult, engage with and support Aboriginal people' (Chaney 2007).

It was a point increasingly strongly argued by those with lengthy experience in these domains. Pearson himself argued: 'The difference between disaster and success will depend on whether Brough and Howard will engage with ... the traditional leaders of the NT on a way forward' (Chaney 2007). Fiona Stanley suggested that 'measures that exclude the views and involvement of Aborigines will serve only to further diminish their capacity, exacerbate marginalisation and add to the damage in these vulnerable communities' (Chaney 2007). Howard was quoted as rejecting criticism that the power structures in Aboriginal communities should be respected, saying they were 'part of the problem'. Implicitly, then, all Indigenous communities (and community leaders) were identified as suffering 'responsibility failure'.

Not only was an approach that would build community capacity (and state community-partnership) fudged, but there was also considerable doubt about the capacity of Commonwealth authorities. 'There is a huge implementation challenge', said Pearson, 'I am not confident they are up to it' (Pearson 2007). 
The legislation, said Fred Chaney, 'authorises an absurd and unobtainable level of micro-management of Aboriginal lives far beyond the capacity of the federal bureaucracy that would permit the notorious protector, Mr Neville, to ride again' (Chaney 2007). A medical anthropologist argued that there is no evidence that micro-management - enforcing compliance with rules and regulations - induces long-term behavioural change. Instead, it demands on-going policing and surveillance. 'Has government got the stomach for this in the long-term?' Chaney later asked (Grattan and Chandler 2007).

In many respects, the way policy was developed in the case of the Northern Territory intervention seems, perversely, as if modelled on the case studies of what produces 'policy fiasco' (Janis 1982; Preston and 't Hart 1999). Decisions were made in haste by a small inner circle, on the advice of a minister who 'talks, but does not listen'. Routine practices of inter-departmental policy consultation were abandoned in the interests of speed. There was no provision for robust debate about alternatives - nor is it clear that expert advice (from economists, medical anthropologists, health professionals, social workers) was sought. Such practices are commonly thought to encourage 'groupthink'. Once legislation was developed, it was pushed through Parliament at speed, making nonsense of the notion of appropriate legislative scrutiny. The explicit concerns of the authors of the report taken as the catalyst for intervention were overlooked. Breaking the cycle seemed to be seen as an end in itself, so there was no apparent thought about the post-intervention phase. Community leaders were defined as 'part of the problem' and so there was no effective community engagement. Yet, without such engagement, there was no prospect of building community capacity or responsibility.

The chance factor - that Brough had an army background and appeared to favour a military approach to policy intervention - alerted commentators to the 'command culture' aspect of the Northern Territory intervention (for example, Schubert and Murdoch 2007a). Several evoked an Iraq parallel by referring to the 'shock and awe' blitz at the core of the government's approach (for example, Grattan and Chandler 2007). Pat Dodson made the connection explicit: 'This is an Iraq style of intervention with no exit strategy or plans for long-term economic and social development' (Dodson 2007). Indeed, just as the invasion of Iraq was premised on the fallacious notion that overthrowing a dictator would unleash the forces of 'freedom' and democracy would follow, the Northern Territory intervention seemed to hinge on equally unfounded assumptions that rules and regulations alone (without attention to the dynamics of dysfunction) would change behaviour and that breaking down the impediments (customary law, collective ownership, etc.) between remote communities and the 'mainstream' would encourage Indigenous people to integrate into the national economy. Given the Howard government's defeat, we can only speculate about how management of the Northern Territory intervention would have progressed, 
but it is probable that the failure of community engagement would have subverted the capacity-building that could be the only foundation for a long-term plan and a viable economy. This missing element - community engagement appears now to be the principal task of the Rudd Labor government.

As suggested earlier, the Northern Territory intervention is far from the only instance where a command culture appeared to operate. I have written elsewhere about 'groupthink' and the Iraq commitment (Walter 2006). With Strangio (Walter and Strangio 2007), I have drawn attention to other instances, such as Howard's unilateral 2002 decision to circumvent defence procurement processes by committing Australia to the hugely expensive US Joint Strike Fighter program, the bypassing of cabinet the same year when announcing Australia would not ratify the Kyoto Protocol, and the 2007 Murray Darling Plan that was originally concocted without reference to cabinet or relevant departments. What we also now know is that Howard brushed aside concerns some ministers raised about WorkChoices, as well as having marginalised alternative viewpoints within government circles on global warming, and blocking proposals for investigating carbon trading schemes in the late 1990s and 2003. As Strangio and I have argued, the trend towards leadership centrality predates Howard, but his practices were integral to the evolution of a command culture in domestic policy making and the increasing resort to crisis techniques indicated it was becoming routinised rather than emerging only in exceptional cases.

\section{Counter-tendencies}

Paradoxically, an antithetical trend was gaining ground in policy circles. Increasingly, the solution to 'wicked' policy problems of the sort that Indigenous community dysfunction represents, has been taken to be devolution of authority and community engagement. A bringing together of the policy community, engaged experts and community representatives in 'learning networks', together with a transfer of authority to act to local levels, was a recurrent topic within debates about contemporary governance (see Head 2005). But such approaches take time and care and will always be denied if, as Howard said about the Northern Territory intervention, 'the time for talking is past'. Yet exercises of this sort have been successfully trialled: local governments in some US jurisdictions have adopted deliberative democracy techniques to determine the allocation of services. Another leading example has been the linking of public agencies, activists, researchers and community groups in restorative (or community) justice initiatives. Are there ways not only of embedding such practices more generally in policy-determination but, also, of carrying such deliberative processes into the parliamentary forum, so that majority consensus is built on key issues rather than being simply asserted by a minister in a hurry, or by a domineering leader? 
In the end, I suspect, there are conflicting cultural tendencies at work. On the one hand, in some policy deliberations there is, as Brian Head shows, an increasing emphasis on community engagement; on dialogue between government and citizens (Head 2007). Gven the declining trust in liberal institutions, it may be only through such engagement that democracy can be rejuvenated, by encouraging processes that allow citizens to 'discover their preferences' (Dahl 1961). Yet it will always be difficult, since the socialisation of policy-makers makes it difficult for them to relinquish control. On the other hand, in a context where old certainties and established institutions are under siege, there is a contradictory current, an atavistic belief that heroic leadership can break through just those 'wicked' issues that seem to be at the base of our difficulties. All, then, depends upon belief — belief in the leader and the leader's self-belief. Policy is judged only on whether the leader believes it is right: the death knell of evidence-based deliberation. In fact, the style of leadership this encourages is good for one purpose only: combat. Yet, as one US army researcher observed, 'a command culture, indispensable in combat, is an impediment to open discussion of fundamental issues at all levels'. In other words, not only does it undermine 'the lattice of leadership', but it is also a style that is inimical to good policy making.

The 'leader as solution' is an assumption evident in many fields, and not just in politics. How else can one explain the astronomical salaries paid to CEOs, the ferocity with which - when any weakness is revealed - they are dispatched, and the recklessness with which we accept their assurances that they are 'the smartest guys in the room' and leave them alone to trigger enormous market failures (such as the corporate collapses of Enron, HIH and Barings)? (see Khurana 2002). Leaders acting unilaterally, closed decision making, and the failure of accountability lead to policy fiasco in every field. When power aggregates at the top, we break democratic connections, losing the capacity to connect the individual to the group, the group to the community, and the community to the state. (These were precisely the connections that were denied in the Northern Territory intervention). The challenge now is how can we develop appropriate channels of community engagement that re-institutionalise liberal constraints, dispel magical thinking about heroic leadership, encourage humility in public officials and devolve power?

\section{Towards the end of the command culture?}

Can a new government overthrow what is described here as a trend, albeit one given powerful impetus by the Howard government's practices and which became more entrenched the longer it held power? Evidently, changes to the machinery of government - enhanced parliamentary scrutiny, the imposition of restraint and accountability on ministerial staff, and restoration of a degree of independence in the public service (Walter and Strangio 2007: ch. 4; Walter 
2008) - would contribute to restoring the 'lattice of leadership' and the Rudd government initially made promising moves on all of these fronts. The appointment of Senator John Faulkner as Special Minister of State to oversee such reform was positive. He was, in opposition, a notable defender of Senate powers of inquiry to ensure proper scrutiny of government. (But, one recalls, Howard also made promises about opening up government on first assuming power). The Rudd team's search for alternative ideas provoked Coalition derision during the 2007 election campaign (Peter Costello's dismissive comment - an exemplary statement of the command culture - was, 'A leader doesn't go to committees, a leader knows what he wants and announces it!'). Yet Rudd's tactics in broadening the scope of policy input (for example, initiating the 2020 summit), committing to community engagement (the community cabinets), and installing representatives of all points of view (for example, appointing Howard's chief of staff and principal adviser, Arthur Sinodinis, to a review of Defence) all seem designed to broaden options, to step back from the leader principle and to hedge against the inner-circle thinking that leads to groupthink. Are they a decisive counter to the command culture?

The other side of the coin is that, on early indications, neither Labor nor Rudd are immune to the cult of leadership. The ALP projected 'Kevin07' as the harbinger of 'new leadership', but tellingly the slogan was personalised and the party gave its fortunes into his hands as completely as it had in the disastrous Latham experiment. Rudd soon gave us a clue to what that might mean by single-handedly overriding Labor's organisational tradition, not with the goal of devolving authority, but centralising it in his hands. Notwithstanding the ALP's expressed intention of addressing the problem of consolidated executive power, some questioned Rudd's ability to do so. A former Foreign affairs colleague of Rudd, for instance, predicted he would be a 'nightmare, an obsessive who would micromanage everything' (The Age, 6 November 2007: 6), and seasoned observers canvassed the indications that he would 'seize more power as PM' (Kelly 2007). Once in power, the commentary on Rudd's predilection for micro-management and his tendency towards a controlling centralisation became more detailed and more persuasive (Taylor 2007; Grattan 2008, Murphy 2008). Yet, at the time of writing, it remained an open question: was the mantra of Rudd's dominance the media feeding on itself (and on an inclination to cast him as Howard in another guise)? Is Rudd clever enough to see the limitations of his penchant for control and to establish countervailing measures? Or is he yet another leader 'steering by power chances' (Davies 1980: 5), for whom the erosion of institutional constraints will prove an irresistible inducement to exercise the command imperative; stalling democratic reform? 


\section{References}

Allison, G., 1971, Essence of Decision: Explaining the Cuban Missile Crisis, Boston: Brown.

Chaney, F., 2007, 'Give Aborigines hope' The Age, 15 August.

Coates, D. and J. Krieger, 2004, Blair's War, Cambridge: Polity Press.

Dahl, R. A., 1961, Who Governs? Democracy and Power in an American City, New Haven: Yale University Press.

Davies, A. F., 1980, Skills, Outlooks and Passions: A Psychoanalytic Contribution to the Study of Politics, Cambridge: Cambridge University Press.

Dodson, P., 2007, 'An entire culture is at stake', The Age, 14 July.

Grattan, M. and J. Chandler, 2007, 'A new dawn?' The Age, 23 June.

Grattan, M., 2008, 'Much to do and to care about,' The Age, 14 March.

Head, B., 2005, 'Governance', in P. Saunders and J. Walter (eds), Ideas and Influence: Social Science and Public Policy in Australia, Sydney: UNSW Press, pp. 44-63.

Head, B., 2007, 'Community engagement: participation on whose terms?' Australian Journal of Political Science, 42:3, pp. 441-54.

Hennessy, P., 2005, 'Rulers and servants of the state: the Blair style of government', Parliamentary Affairs, 58:1, pp. 6-16.

Hocking, J., 2005, 'Liberty, security and the state', in P. Saunders and J. Walter (eds) Ideas and Influence: Social science and public policy in Australia, Sydney: UNSW Press, pp. 178-197.

Janis, I., 1982, Groupthink: Psychological Studies of Policy Decisions and FIascos, Boston: Houghton Mifflin.

Kampfner, J., 2003, Blair's Wars, London: The Free Press.

Karvelas, P., 2007b, 'Tactic a backward step, say authors', The Australian, 11 August.

Karvelas, P., 2007a, 'Moved by Pearson's passion, The Australian, 23-24 June.

Kelly, P., 2005, Re-thinking Australian Governance: The Howard Legacy, Cunningham Lecture 2005, Occasional paper series 4/2005, Academy of the Social Sciences in Australia, Canberra.

Kelly, P., 2007, 'Rudd would seize more power as $\mathrm{PM}^{\prime}$, The Australian, 7 November.

Khurana, 2002, Searching for a Corporate Savoir, Princeton: Princeton University Press. 
Kouzmin, A., 2008, 'Crisis management in crisis?' Administrative Theory and Praxis, 30:2 (forthcoming).

Marrs, J., 2001, Rule by secrecy, New York: Perennial.

McAllister, I., 2008, 'Political Leaders in Westminster Systems', in K. Aarts, A. Blais and H. Schmitt (eds) Political Leaders and Democratic Elections, Oxford: Oxford University Press, (forthcoming).

Murphy, K., 2008, 'Rudd's will to power', The Age, 29 March.

Pearson, N., 2000, Our Right to Take Responsibility, Cairns: Noel Pearson and Associates.

Pearson, N., 2007, 'An end to the tears', The Australian, 23-24 June.

Poguntke, T. and P. Webb (eds), 2005, The Presidentialization of Politics: A Comparative Study of Modern Democracies, Oxford: Oxford University Press.

Preston, T. and P. 't Hart, 1999, 'Understanding and Evaluating Bureaucratic Politics: The Nexus Between Political Leaders and Advisory Groups', Political Psychology, 20:1, 49-98.

Rothwell, N., 2007 'Desert sweep', The Australian, 11-12 August.

Schubert, M. and L. Murdoch, 2007a, 'Cyclone Mal rips through Territory troubles', The Age, 23 June.

Schubert, M. and L. Murdoch, 2007b, 'Child abuse crackdown on benefits', The Age, 23 June.

't Hart, P., U. Rosenthal and A. Kouzmin, 1993, 'Crisis decision-making: the centralization thesis revisited', Administration and Society, 25:1, pp. $12-45$.

Taylor, L., 2007, 'Method man', AFR Magazine, 23 February.

Uhr, J., 2005, Terms of Trust: Arguments over Ethics in Australian Government, Sydney: UNSW Press.

Walter, J., and P. Strangio, 2007, No, Prime Minister: Reclaiming Politics from Leaders, Sydney: UNSW Press.

Walter, J., 2006, 'Why prime ministers go too far', in D. McDougall and P. Shearman (eds) Australian Security After 9/11: New and Old Agendas, London: Ashgate, pp. 189-206.

Walter, J., 2007a, 'Political Leadership', in B. Galligan and W. Roberts (eds) Oxford Companion to Australian Politics, Melbourne: Oxford University Press, pp. 428-30.

Walter, J., 2007b, 'Political Leadership', in G. Rizer (ed.), The Blackwell Encyclopedia of Sociology Vol VII, Oxford: Blackwell, pp. 3441-5. 
Walter, J., 2008, 'Neither fear nor favour', The Age, 25 March.

Wanna, J. and P. Williams, 2005, Yes, Premier: Labor leadership in Australia's States and Territories, UNSW Press.

Weller, P., 2002, Don't Tell the Prime Minister, Melbourne: Scribe Publications.

Weller, P., 2007, Cabinet Government in Australia, 1901-2006: Practices and Principles, Sydney: UNSW Press.

Wild, R. and P. Anderson, 2007, Ampe Akelyernemane Meke Mekarle: 'Little Children are Sacred', Report of the Northern Territory Board of Inquiry into the Protection of Aboriginal Children from Sexual Abuse, Northern Territory Government, Darwin.

Wild, R., 2007, 'Child abuse inquiry head criticises Govt reponse', Lateline Business, Australian Broadcasting Corporation, 27/06/2007, at http://www.abc.net.au/lateline/content/2007/s1964086.htm, accessed 18 March 2008. 